PHYSICAL REVIEW E 73, 049906(E) (2006)

\title{
Erratum: Structure of positive decompositions of exponential operators [Phys. Rev. E 71, 016703 (2005)]
}

Siu A. Chin

(Received 14 November 2005; revised manuscript received 28 March 2006; published 19 April 2006)

DOI: 10.1103/PhysRevE.73.049906

PACS number(s): 02.70.Ss, 02.70.Ns, 95.10.Ce, 99.10.Cd

The coefficient $e_{\mathrm{TVT}}$ is a typographical error that should read $e_{\mathrm{VTV}}$ in Eq. (2.12). Also, the last three equation in (4.11) should read:

$$
\begin{gathered}
g_{33}=\kappa(1,3)+\kappa(2,1) \\
g_{34}=\kappa(1,4)+\kappa(2,2) \\
g_{44}=\kappa(1,5)+\kappa(2,3)+\kappa(2,1) .
\end{gathered}
$$

These follow from (4.5), (4.6), and (4.10) and can be easily verified. The conclusion of the paper is not changed by these typographical errors.

Eq. (2.27) only applies to algorithms whose $e_{\mathrm{VTV}}$ is stationary with respect to $\left\{u_{i}\right\}$ subject to constraints (2.15) and (2.16). I thank Dr. S. Blanes and Dr. F. Casas for pointing out that Eq. (2.27) does not apply in the most general case for the purpose of deriving the Goodman-Kaper [1] result. Triggered by their comment, I have since proved a fundamental theorem from which the general Goodman-Kaper result can be derived as a corollary [2]. I have also shown that Eq. (2.27) can be used to derive a wide class of fourth-order algorithms [3]. I thank Dr. Blanes and Dr. Casas for their most helpful observation.

[1] D. Goldman and T. J. Kaper, SIAM (Soc. Ind. Appl. Math.) J. Numer. Anal. 33, 349 (1996).

[2] S. A. Chin, "A fundamental theorem on the structure of sym- plectic integrators," Phys. Lett. A, in press, avaliable online 10 February 2006.

[3] S. A. Chin, Phys. Rev. E 73, 026705 (2006). 